\title{
As influências das ideologias do trabalhismo, da negritude e da democracia racial nas demandas por educação da população negra brasileira*.
}

\author{
Arilson dos Santos Gomes ${ }^{1}$
}

RESUMO: Este artigo pretende problematizar as relações entre as ideologias do trabalhismo, da negritude e da democracia racial na concretização das demandas reivindicadas pela população negra brasileira na elaboração das políticas educativas. Entre as décadas de 1930 a 1960, período em que essas ideias surgiram e se estabeleceram na sociedade brasileira, as populações negras cientes dos valores políticos produzidos naquele momento passaram a negociar, por meio de seus líderes em conjunto com os partidos políticos, as condições necessárias às suas melhorias materiais. Por outro lado, percebeu-se nos programas políticos de determinados partidos, preocupações com a questão racial. Entende-se que as demandas educativas atuais foram reflexos das negociações históricas, advindas das ideologias citadas, formuladas por grupos políticos e seus respectivos intelectuais.

Palavras-chave: Ideologias; Negociações; População Negra

ABSTRACT: This article aims to discuss the relationship between the ideologies of labor, of blackness and racial democracy in achieving the demands claimed by black people in educational policy-making. Among the 1930 to 1960 period in which these ideas emerged and established themselves in brasilian society, the black populations aware of the political values produced at that time started to negotiate, through their leaders together with the political parties, the conditions necessary to their material improvements. Moreover, it was noticed in the programs of certain political parties, concerns about racial issues. It is understood that the current educational demands were reflections of historic negotiations, resulting ideologies mentioned, formulated by political groups and their intellectuals.

Keywords: Ideology; Trading; Black Population

\section{Introdução}

O termo ideologia apareceu em 1801 no livro do autor Destutt de Tracy (1754-1836), intitulado: Eléments d'Ideologie (Elementos de Ideologia). Segundo Marilene Chauí (1989) seu autor pretendia elaborar uma gênese das ideias (CHAUÍ, 1989:21-25). Marx definiu a

\footnotetext{
* Artigo submetido em 04 de maio de 2013 e aprovado em 15 de julho de 2013.

${ }^{1}$ Professor de História da Faculdade Porto-Alegrense (FAPA). Doutorando em História (PPGH-PUCRS). Coordenador do GT-Negros (ANPUH-RS). Pesquisador do Grupo Africanidades, Ideologias e Cotidiano (PPGH-PUCRS).
} 
ideologia como um sistema de ideias de justificação das relações sociais, em beneficio da classe dominante. Pesquisas posteriores aprofundaram as analises da função social e política das ideologias e as suas elaborações por meio dos aparelhos de Estado e de intelectuais, que seriam os mediadores das ideias advindas dos grupos sociais junto às instituições (ALTHUSSER, 1992:76; Gramsci apud PORTELLI, 1977:24; Fossaert apud WINOCK, 2003:286; Marx apud WINOCK, 2003:271).

Busca-se neste trabalho interpretar se as ideologias políticas produzidas por grupos organizados no país e de seus intelectuais, ao longo dos anos de 1930 até 1960, identificadas no trabalhismo, na negritude e na democracia racial, constituíram-se como bases das negociações políticas alusivas as demandas educativas da população negra e quiçá influenciaram na formulação das então denominadas ações afirmativas brasileiras, instituídas a partir de 2003. Elaboradas pelo Estado a fim de atenuar as diferenças materiais entre os grupos negros e os demais grupos formadores de nossa sociedade, essas políticas foram oriundas das negociações de representantes dessas causas junto aos grupos políticos. Essas políticas ainda são muito discutidas no âmbito acadêmico, político e social. Acredita-se que pensar nessas ações, como oriundas das negociações ideológicas, tornam-se fundamental, pois elas carregam a intensidade dos valores e sistemas das ideias citadas.

As produções das culturas e de suas respectivas ideologias ficam a cargo dos intelectuais orgânicos surgidos no seio de cada grupo ${ }^{2}$. Portanto, o trabalhismo, a negritude e a democracia racial foram elaborados por intelectuais representantes de determinados grupos, em uma tensão constante entre as crenças e o vivenciado pelas populações atingidas por suas ideias e que igualmente deram as bases para suas construções, conforme analisaremos. As ações em torno dessas ideias por meio de seus representantes foram tensas, mas como afirma René Rémond (2003:18): “as políticas públicas são resultados das interações entre vários fenômenos sociais"; e porque não culturais e ideológicos?

\section{Trabalhismo e demandas negras}

Após o período conhecido como Estado Novo (1937-1945), a redemocratização foi marcada pela intensa agitação política, advinda das negociações em que, por meio de suas ideologias, novos grupos ou classes, até então sem forte participação nas instâncias de poder,

\footnotetext{
${ }^{2}$ Constituído por uma elite de homens de cultura, que tem a função de dirigir do ponto de vista da cultura as massas. Para saber ver GRAMSCI, 1980, p.23. 
passam a reivindicar melhores condições materiais e representação na política brasileira. $\mathrm{O}$ modelo político para equilibrar as tensões da incipiente democracia foi identificado na ideologia trabalhista promovida pelo estado e pela mobilização dos movimentos sociais originadas com este processo, os quais passam a ter espaço no período conhecido como populismo ou do pacto trabalhista, que iriam sofrer um duro revés em 1964 com a ditadura civil-militar. $^{3} \mathrm{Na}$ realidade, a raiz desse fenômeno, também denominado estado de compromisso ou de equilíbrio, surge nos anos de 1930 com o declínio hegemônico das oligarquias do café e a ascensão de novos grupos na arena da disputa política, visando a oferecer ao Estado as bases de sua legitimidade, conforme apontaram algumas pesquisas (WEFFORT, 1973; GOMES, 1988:343; FAUSTO, 2002:328). Se os líderes negros não percebessem as condições sociais dessa época, então como explicar a criação da Frente Negra Brasileira no intuito de concorrer a cargos públicos, já no ano de $1937^{4}$.

Salienta-se que a força política do PTB, partido criado pelas ideias getulistas, concentrava-se na mobilização política do seu projeto, direcionado à classe trabalhadora e engendrado, de acordo com Fortes, "a partir da segunda metade do Estado Novo, com a capacidade de se apresentar como expressão única da classe no período". Não obstante, as mudanças ocorridas geraram articulações de coexistências estratégicas criativas para os trabalhadores, individuais e coletivas. Surgia na política institucional um espaço de mudanças "marcado pela tensão, flexibilidade de costumes e a circulação de valores" possibilitando a luta por cidadania e pelas demandas dos trabalhadores, em que pese o paternalismo, as fissuras consistiram em possibilidades de ações (FORTES, 2004:20-28).

Em fevereiro de 1945, com o chamado Ato Adicional à carta de 1937, Getúlio Vargas (1882-1954) fixou um prazo de 90 dias para a realização de eleições gerais em nosso país. Era a abertura democrática iniciada no final da II Guerra e do Estado Novo. Com o novo

\footnotetext{
${ }^{3} \mathrm{O}$ golpe contou com um apoio de um amplo movimento civil de classe média, organizado pela maioria das representações ideológicas da burguesia - partidos, grande imprensa e setores da Igreja.

${ }^{4}$ A Frente Negra Brasileira foi fundada em São Paulo no dia 16 de setembro de 1931 por Arlindo Veiga dos Santos (1902-1978). No decorrer de sua trajetória, de setembro de 1931 até dezembro de 1937, a organização foi presidida por Arlindo Veiga dos Santos, que ocupou o cargo até junho de 1934, e por Justiniano Costa, que ocupou a presidência até a extinção da organização. Em uma das negociações entre essa organização e o presidente Getúlio Vargas, os negros passaram a ser admitidos na guarda paulistana, antes não era permitido sequer o alistamento de membros dessa comunidade. No Rio Grande do Sul, a Frente Negra Pelotense foi fundada no dia 10 de maio de 1933 por José Adauto Ferreira da Silva, Carlos Torres, José Penny, Humberto de Farias e Miguel Barros, sendo que, este último, também fora fundador da Frente Negra de Pernambuco. Tinham como atividades, em suas dependências, a realização de cursos e seminários para a comunidade negra direcionados para a educação e a união. Dentre os seminários direcionados estavam a "reabilitação e engrandecimento de todos os elementos da raça", e temas como: "A mulher negra e o futuro da raça".
} 
código eleitoral, estavam dadas as condições para as eleições para presidente, além de uma Assembleia Constituinte, sendo que a data escolhida para a realização dos pleitos estaduais era o dia 6 de maio de $1946^{5}$.

Ressalta-se que as Forças Armadas também compuseram esse cenário, visto que jamais foram indiferentes à participação política e às disputas de poder, desde a promulgação da República ${ }^{6}$. Inclusive, sendo responsáveis pela tendência democratizante no Brasil após a II Guerra Mundial, derrubando a ditadura de Vargas em 1945, já que, com a vitória dos aliados sobre o fascismo, transformaram as relações políticas brasileiras, antes centralizadoras e agora liberais.

Segundo Mota, que pesquisou a cultura brasileira com o propósito de identificar a origem das ideias de consciência nacional ou cultura nacional, foi nesse período que se consolidou um sistema ideológico com múltiplas vertentes interligadas: neocapitalista, liberal, nacionalista, sindicalista, desenvolvimentista e marxista. Porém, o autor cita que para o proletariado surgiram novas oportunidades em virtude da legislação social (MOTA, 1980:156-160) Representantes das causas negras vislumbraram um momento propício às suas demandas na arena política.

No campo da disputa política para enfrentar a "redemocratização", mesmo fora do poder, Vargas cria dois partidos, dirigidos a diferentes clientelas: o Partido Social Democrático - PSD e o Partido Trabalhista Brasileiro - PTB. O primeiro reunia ruralistas, banqueiros, industriais e altos administradores, e o segundo, que além de reunir representantes da burguesia urbana, se concentrava na organização da liderança trabalhista (SADER, 1982:138). Porém, Ferreira explica que, no Rio Grande do Sul, o PTB foi fundado exclusivamente por um grupo de sindicalistas, que, desde os anos de 1930, lutavam por leis sociais e reconhecimento político. O historiador assevera que a fundação do partido no estado, por José Vecchio, em 1945, foi o resultado das tradições que circulavam entre os próprios trabalhadores, antes e depois de 1930. O PTB, em última análise, era para ele a institucionalização do trabalhismo em um partido político (FERREIRA, 2004:279-294).

\footnotetext{
5 A Assembleia Nacional Constituinte é um organismo colegiado que tem como função redigir ou reformar a constituição, a ordem político-institucional de um Estado, sendo para isso dotado de plenos poderes ou poder constituinte, ao qual devem submeter-se todas as instituições públicas.

6 A própria Proclamação da República bem como o Tenentismo e posteriormente, a criação da ESG representavam as preocupações dos militares com as questões políticas. 
Foi nos interstícios destes cenários políticos e sociais que os representantes das comunidades negras, passaram a tencionar, por meio de suas ações, os poderes públicos constituídos em busca da fundação e da institucionalização das políticas sociais, condizentes com as suas realidades. Pois, afinal de contas, os negros escravizados constituíram-se durante um longo período da história como os principais trabalhadores do país, entretanto, com poucos ganhos coletivos materiais. O trabalhismo, com os seus limites, permitiu as negociações dos grupos e de seus interesses com o estado.

O período analisado foi importante para a potencialização das demandas inclusivas da identidade negra, visto que ocorreram no país, entre os anos de 1946 a 1958, quatro grandes congressos nacionais para propor ao poder público que possibilitassem as tão esperadas melhorias dos aspectos sociais cotidianos das populações negras (GOMES, 2008). A partir deste período conseguiu-se identificar que as negociações políticas em torno das demandas negras, por meio de suas lideranças, intensificaram-se em diversas regiões do país com destaque para Bahia, São Paulo, Rio de Janeiro e Rio Grande do Sul.

\section{Associações negras e a ideologia da negritude}

A organização União dos Homens de Cor - UHC, com ramificações em 11 estados da federação, conforme apontaram as pesquisas de Joselina Silva (2003), foi fundada em 1943 na cidade de Porto Alegre, por João Cabral Alves, ainda em pleno Estado Novo, por isso uma característica dessa organização era o assistencialismo, tendo suas atividades encerradas no período da ditadura militar de 1964. Tinha como um dos seus objetivos, expressos no artigo $1^{\circ}$ do estatuto, no capítulo das finalidades: "elevar o nível econômico e intelectual das pessoas de cor em todo o território nacional, para torná-las aptas a ingressarem na vida social e administrativa do país, em todos os setores de suas atividades" ${ }^{7}$, principalmente por meio da assistência social. Joselina Silva concluiu que a UHC pode ser considerada como um "renascimento negro" em termos organizativos, visto que o Estado Novo encerra as atividades políticas no país, incluindo as organizações negras em 1937 (SILVA, 2003:215-235). Petrônio Domingues chamou a atenção para sua escalada expansionista da UHC (DOMINGUES, 2007:108). Na segunda metade da década de 1940, ela abriu filiais em, pelo menos, 10 Estados da Federação (Minas Gerais, Santa Catarina, Bahia, Maranhão, Ceará, Rio Grande do

\footnotetext{
${ }^{7}$ Estatuto da União dos Homens de Cor do Brasil - (Uagacê). Jornal A Alvorada, Pelotas, ano 53, n.22, 1951, p.01.
} 
Sul, São Paulo, Espírito Santo, Piauí e Paraná), estando presente em inúmeros municípios do interior. Em 1948, somente no estado do Paraná, a UHC mantinha contato com 23 cidades.

Nesse contexto, surgiu o Teatro Experimental do Negro - TEN, fundado na cidade do Rio de Janeiro no ano de 1944, no final da vigência do Estado Novo, pelo intelectual negro Abdias do Nascimento. Tinha por intuito, além de produzir peças teatrais, motivar o negro, por meio da alfabetização, a combater a discriminação e o preconceito racial que existia na sociedade carioca. Funcionava em sede emprestada pela União Nacional dos Estudantes (UNE), na Praia do Flamengo. Para Nascimento, era inadmissível, em um país como o nosso, que na década de 1940 contava com uma população de 60 milhões de habitantes, composta por 20 milhões de pessoas negras, que os diretores artísticos escalassem artistas brancos para as peças teatrais podendo estrelar com atores negros (GOMES, 2008:122-136).

O TEN organizou concursos de artes plásticas, concursos de beleza que enalteciam os padrões afro-brasileiros e eventos sociopolíticos. Também foi nessa organização que se cogitou uma medida constitucional para a criação de uma legislação antirracista, além da produção de um periódico, intitulado "Jornal Quilombo" (NASCIMENTO, 2000:210). O jornal Quilombo: vida, problemas e aspirações do negro; divulgou trabalhos do TEN em todos os seus campos de ação, entre 1948 e 1951. O jornal trazia reportagens, entrevistas, e matérias sobre assuntos de interesse à comunidade. A precariedade dos recursos financeiros do TEN, e do poder aquisitivo de seu público, não lhe permitiu uma permanência maior (NASCIMENTO, 2004:223). A Convenção Nacional do Negro Brasileiro foi uma ação realizada em São Paulo (1945) e no Rio de Janeiro (1946) sob a liderança de Abdias do Nascimento (1914-2011), que apresentou o "Manifesto a Nação Brasileira”, interpelando os partidos da época sobre a situação das populações negras, em sua grande maioria vivendo em favelas (CEVA, 2006:72-73). ${ }^{8}$ As atividades, somadas, contaram com a participação de 700 pessoas. Destaca-se que, em 1946, o Brasil estava formando a Assembleia Constituinte. O

\footnotetext{
${ }^{8}$ Abdias do Nascimento foi fundador do TEN (1944). Educava as populações negras por meio do teatro. Para saber mais da Proposta Pedagógica do TEN, ver: CEVA, Antônia Lana de Alencastre (2006). O Negro em Cena: a proposta pedagógica do Teatro Experimental do Negro (1944-1968). Ceva concluiu que: "O TEN, mesmo com uma atuação breve (1944-1968), e devido à falta de patrocínio e de espaço físico próprio para a sua continuidade, mantém na contemporaneidade, se compararmos com as entidades atuais do movimento negro, as suas demandas. A educação é uma forma de luta contra a discriminação racial” e segue a autora: “(...) A Frente Negra (1931-1937) e o TEN (1944-1968) fizeram da educação sua principal estratégia de ação, para transformar a situação social do negro/a na sociedade brasileira". CEVA, Antonia Lana de Alencastre. O negro em cena: a proposta pedagógica do Teatro Experimental do Negro. 124 f. (Mestrado em Educação) PUC-RJ, Rio de Janeiro, 2006, p.72-73.
} 
manifesto redigido nas convenções, em sua fundação, continha uma série de reivindicações sociais (NASCIMENTO, 1982:112-113).

O documento da Convenção recebeu apoio dos seguintes partidos e políticos: UDN, representada pelo senador Humberto Nogueira, PCB, representado por Luís Carlos Prestes e PSD. O senador Humberto Nogueira apresentou o documento à Assembleia Constituinte, entretanto, no momento de se institucionalizar a "proibição da discriminação racial", fundada/escrita no manifesto, na Constituição do país, se estabeleceu no texto "a igualdade de todas as raças". O PCB, que apoiou a fundação do manifesto, colocou-se contra a inserção do item "proibição da discriminação racial" na Constituição, pois a lei antidiscriminatória restringiria, segundo os comunistas, "o sentido mais amplo de democracia" (SANTOS, 2009:129). Estavam insatisfeitos e atentos às demandas do período, em que negros eram discriminados em barbearias, clubes e sociedades, os intelectuais negros do TEN, dos quais citamos o intelectual Alberto Guerreiro Ramos (1915-1982), considerado ideólogo da negritude na organização. ${ }^{9}$ Ressalta-se que, tendo como ideologia a bandeira da negritude, o grupo passou a ser acusado de racista às avessas, tanto por grupos de direita ligados à UDN, como por grupos da esquerda, ligados ao Partido Comunista (NASCIMENTO, 2000:214). Essa situação identifica as tensões existentes entre as forças políticas da época.

Entende-se que a identidade negra vem sendo construída politicamente ao longo das décadas republicanas pela intensa produção simbólica referenciada nas demandas inclusivas proporcionadas pelas negociações deste grupo com a sociedade abrangente. As associações negras em conjunto com a imprensa negra assinalaram nesse sentido, já que propuseram ações que elevassem a condição cultural, política e social deste grupo. Da autoestima ao reconhecimento da instrução como forma de qualificar-se na disputa por emprego, estas iniciativas positivaram a negritude, que durante a escravidão bem como no pós-abolição, continuava estigmatizada.

\footnotetext{
${ }^{9}$ O dirigente do Grupo, responsável teórico direto por este setor de atividades foi Alberto Guerreiro Ramos. Para Pinto (1954, p.292), é a partir destas atividades que surgiu a bandeira de luta de forte conteúdo emocional e místico, capaz de se propagar, de despertar, de arrastar os homens negros com a força estimulante que têm as grandes ideias e as mensagens redentoras, a ideologia da negritude. Para L.C. Pinto (1953, p.293), artistas, poetas, escritores, pequena elite intelectual negra, homens de sensibilidade multiplicada pelo choque de sua vocação, seu temperamento e suas ambições de encontro à realidade de classe e de raça em que estão situados, racionalizaram a sua queixa e transformaram sua cor, fonte, muitas vezes, de dissabores, num valor supremo para eles, sob o qual se abrigam para dizerem, "sem medo e sem vergonha": niger sum! Para Pinto a negritude era um mito, uma concepção invertida e mistificada das coisas.
} 
Para o historiador Petrônio Domingues, o movimento da negritude, surgido por volta de 1920, nos Estados Unidos, cumpriu um papel revolucionário. Na fase inicial, percorreu as Antilhas e a Europa e, após, a África. No Brasil, em meados de 1950, esse conceito rompeu com os valores da cultura eurocêntrica: "no campo ideológico, negritude pode ser entendida como processo de aquisição de uma consciência racial. Já na esfera cultural, negritude é a tendência de valorização de toda manifestação cultural de matriz africana" (DOMINGUES, 2005:25-40).

Portanto, negritude é um conceito multifacetado, que precisa ser compreendido a luz dos diversos contextos históricos. No entanto, ainda segundo Domingues, "na medida em que o conceito se ampliou, o mesmo adquiriu uma conotação mais política, diluindo o seu potencial transformador" (DOMINGUES, 2005:26). O movimento passou a padecer de contradições insolúveis, "a ponto de alguns de seus principais dirigentes defenderem posições políticas conservadoras". Domingues examinou a negritude por intermédio de pesquisadores brasileiros, africanos, americanos, antilhanos e europeus (BERND, 1984; MUNANGA, 1988; NASCIMENTO, 1982; FANON, 2008; MEMMI, 1989), identificando que o movimento da negritude, por intermédio de Du Bois (EUA 1868-1963), Aimé Césaire (Martinica), Léon Damas (Guiana Francesa) e Léopold Sédar Senghor (Senegal), reivindicava, entre outros fatores, a consciência do negro civilizado, o renascimento do negro no campo artístico e literário, conjugado aos valores africanos, além de possibilitar o reconhecimento político cotidiano local e internacional dos afrodescendentes, por ocasião das independências dos países daquele continente, logicamente, além de enfatizar o orgulho racial. Com contradições, visto que independentemente do território em que os intelectuais afrodescendentes a formularam, utilizavam a língua do colonizador, perdeu autenticidade. Porém, para Petrônio Domingues, a negritude encontra limites na medida em que a negritude se esgota na tarefa de despertar uma consciência racial, ou seja, na preocupação de responder estritamente às contradições raciais, fazendo o negro reconhecer-se e identificar-se simplesmente pela cor da pele, deixa-o alienado das demais contradições que se operam na sociedade (DOMINGUES, 2005:25-40). Algo que, possivelmente, será ultrapassado na medida em que a própria democracia brasileira, em todas as suas instâncias culturais, políticas e sociais, obter maior qualidade no debate e ações em torno da aceitação das diferenças étnico-raciais existentes. Embora, perceba-se, a complexidade do tema, reconhece-se que a problemática causada pela falta de políticas públicas irrealizadas após o período conhecido de pós-abolição além das 
mazelas produzidas pelas escolas racistas do início do século $\mathrm{XX}$, prejudicou a nossa sociedade independentemente da epiderme das pessoas. Já que mesmo com as contradições sociais existindo o estigma, identificado no imaginário social legado as populações negras de diversas maneiras, persiste. Mesmo com nítidos avanços.

Retornando às atividades organizadas pelos integrantes do TEN, Abdias do Nascimento, com o auxílio de Edison Carneiro, organizou a Conferência do Negro (1949) e o Congresso do Negro Brasileiro (1950), ambas na cidade do Rio de Janeiro. Representantes da Sociedade Floresta Aurora de Porto Alegre, Heitor Nunes Fraga, José Pedrosa e o pesquisador gaúcho Dante Laytano (1908-2000) estiveram presentes nessas atividades. ${ }^{10}$ Como resultado desses encontros, a comunidade negra passa a reivindicar com força as suas demandas, fazendo com que os poderes constituídos passem a se preocupar com a questão do preconceito racial vinculados aos aspectos sociais desse grupo. Nesse contexto, surgiu a lei Afonso Arinos. ${ }^{11}$

Nesse período, Edison Carneiro (1912-1972), um dos intelectuais organizadores do II Encontro Afro-Brasileiro da Bahia, realizado em 1937, articulador da Conferência e do Congresso do Negro de 1949 e 1950, passou a ser contrário aos ideais de Abdias do Nascimento e de Guerreiro Ramos. ${ }^{12}$ Para Carneiro, a situação social do negro e dos estudos afro-brasileiros, desde o século XIX, seguia em nosso país, apesar das dificuldades e de sua fase inicial, obtendo avanços significativos. Porém, conforme afirmou sobre a postura do TEN, a partir desse momento ela passou a ser equivocada, pois a situação do negro brasileiro

\footnotetext{
${ }^{10}$ Segundo Liane Muller a Sociedade Floresta Aurora foi fundada na cidade de Porto Alegre no dia 31 de dezembro de 1872, essa agremiação é considerada a sociedade negra mais antiga do Brasil. Seu fundador foi o negro forro Polydorio Antonio de Oliveira. O principal objetivo da organização era zelar pela Comunidade afrogaúcha materialmente e socialmente, auxiliando, inclusive, na realização de enterros dignos para os negros da capital. MULLER, Liane Susan (1999). Em outra pesquisa Sobre a fundação da Sociedade Floresta Aurora, Eliane Pereira Duarte fez a seguinte observação: “... a sociedade Floresta Aurora foi fundada no ano 1872, por negros cativos de senzala... Contam que tudo começou com uma negra forra que vivia no arraial da Floresta ... que chamava-se Mariquinha”. DUARTE, Eliane Pereira (1986:6).

${ }^{11}$ O Projeto $N^{\circ} 562$ - 1950, mais conhecido como Lei Afonso Arinos, era composto por 8 artigos. Em linhas gerais a Lei instituía como contravenção penal o estabelecimento que recusasse hospedar, servir e atender negros. Crime passivo de multa de Cinco Mil Cruzeiros ou prisão de quinze dias a três meses. Ou até o fechamento de estabelecimentos que desrespeitassem negros. Lei na íntegra no O Jornal Quilombo, Junho e Julho de 1950, Ano II, nº10, p.09.

12 O segundo Congresso Afro-brasileiro, de 1937, foi organizado em 1937 por Edison Carneiro, Aydano do Couto Ferraz (1914-1985) e Reginaldo Guimarães. Ver: Prefácio à publicação de O Negro no Brasil: trabalhos apresentados ao $2^{\circ}$ Congresso Afro-Brasileiro reunido (Bahia) de 1937. Civilização Brasileira, Rio de Janeiro, 1940 (CLAY, 2008).
} 
era muito diferente da dos negros dos Estados Unidos. ${ }^{13}$ Carneiro também acreditava que essa nova posição negra, em nosso país, era uma ideologia sustentada por uma minoria, influenciada pelos políticos profissionais: "um avultado grupo de pequeno-burgueses e burgueses intelectuais de cor tentou dar voz a manifestações racistas, de supremacia emocional do negro a fórmula norte-americana, esta americanização forçada do problema, que felizmente atinge apenas um segmento insignificante da população de cor” (...) (CARNEIRO, 1964:115-116). Destacamos que Edson Carneiro, como intelectual, tinha outros propósitos na época, pois lutou incansavelmente para criar um Centro de Estudos Afro-Orientais (CEAO) na Bahia (GOMES, 2012:5-22). Todavia, os intelectuais negros procuravam mediar as necessidades da maioria das populações negras, carentes, já que o contexto, como observamos, permitia tais negociações.

Conforme Sales dos Santos, "a tentativa dos movimentos negros de atuarem no parlamento, visando ao combate ao racismo, se dava por meio de intermediários que não eram militantes orgânicos desse movimento" (SANTOS, 2009:127). As lideranças desses movimentos sociais já haviam percebido, há algum tempo, que precisavam de representantes afro-brasileiros engajados na luta antirracista no Congresso Nacional (SANTOS, 2009:134135). A Frente Negra (1931-1937) arregimentou associados, visando a tornar-se partido político, projeto cancelado em virtude do decreto do Estado Novo.

Não obstante, além de negociar com as lideranças políticas, indivíduos negros também procuravam se eleger com a abertura política no início dos anos de 1950. O próprio Abdias do Nascimento escreveu no editorial do Jornal Quilombo dos meses de março-abril, de 1950, as seguintes fundações:

Amigos meus colaboradores e simpatizantes do movimento que fundamos visando à elevação cultural e econômica do negro brasileiro; resolveram lançar minha candidatura à assembleia legislativa do Distrito Federal. Justificaram seu gesto com argumento de ser minha eleição a vereador uma etapa lógica e natural no desenvolvimento desse programa de busca de meios (sic) que acelerem o processo de integração de brancos e negros no Brasil, assegurando assim, à tática por nós usadas (sic) (...) armas mais efetivas e poderosas na luta pela conquista desse padrão de existência ideal que libere os brasileiros de cor de complexos emocionais e das atuais

\footnotetext{
13 "Na década de 1950 os negros norte-americanos reagiram contra a situação de inferioridade e exclusão que as leis dos brancos o condenaram. Ergueram-se contra a discriminação e a segregação racial que sofriam no país... que o impediam-nos de votar e de freqüentar uma escola pública como os demais brancos. Negavam-lhes hospedagem nos hotéis e nem em lanchonetes eram atendidos". Neste contexto foi que surgiu o Civil Rigths Movement que teve como um de seus maiores expoentes o reverendo Martin Luther King (SCHILLING, 2003). 
desvantagens sócioeconômicas (...) é necessário e imprescindivel, portanto que apareçam outros candidatos mulatos, negros ou brancos, identificados com esse importante problema brasileiro. Porque somente num grande e árduo trabalho coletivo, presidido pelo alto espírito de fraternidade racial que orientou a nossa formação histórica, conseguiremos realizar a obra dessa valorização do negro, fundamental para o desenvolvimento e o futuro de nossa estremecida pátria. Os homens de cor, ontem como hoje, se confundem com os destinos da nacionalidade, e não há força capaz de induzi-los atrás sua vocação de maiores construtores materiais e espirituais da nossa grandeza, da grandeza do Brasil. (Grifos Nossos) (NASCIMENTO, 1950:83).

No editorial do Jornal Quilombo, acima citado, localizam-se entre os conteúdos grifados as seguintes afirmações: “(...) que apareçam outros candidatos mulatos, negros ou brancos, identificados com esse importante problema brasileiro (...)”, “(...) fraternidade racial que orientou a nossa formação histórica (...)" e “(...) Os homens de cor, ontem como hoje, se confundem com os destinos da nacionalidade (...)". Nessas passagens, são sentidas as fortes influências do nacionalismo presente desde o Estado Novo, e que norteiam as bases ideológicas do trabalhismo (Cf. NASCIMENTO, 1950:83).

\section{A democracia racial e as negociações políticas: exemplos do Rio de Janeiro ao Rio Grande do Sul}

A ideologia nacionalista, em sua questão racial, encontra sentido em nosso entendimento na tão discutida e criticada ideologia da democracia racial (BENTO, 2002:189). Todavia, é por meio desse conjunto de significações simbólicas culturais, criadas a partir dos grupos formadores da nação (HALL, 2003), que os grupos negros conseguem formular suas estratégias de negociações políticas na década de 1950, já que o contexto permitia, além do reconhecimento cultural, advindo das décadas anteriores, negociações políticas e sociais, envolvendo as lideranças das comunidades negras, pois esses aspectos passam a estar em evidência devido a uma maior participação das massas no processo de redemocratização. É um anacronismo ou uma falta de sensibilidade com as ações daqueles líderes e de suas organizações pensar nessa ideologia, nos dias atuais, sem contextualizar a época, optando pelo reconhecimento cultural do negro como alguém que deve representar seus anseios a partir da África e de Zumbi ou da data alusiva à consciência negra, referenciando o dia 20 de novembro ao invés do dia 13 de maio, data comemorada pelos grupos negros após a abolição e até meados dos anos de 1970. Tais líderes e suas associações, por meio dos referenciais da época, conseguiram, ao menos, fazer política, pois as suas demandas como líderes das 
populações negras, a partir daquele conjunto de ideias, permitiam a tensão com os poderes públicos constituídos (ZUBARAN, 2011). Outro fator é que tanto o estado (como poder instaurador), como a sociedade, passaram a legitimar simbolicamente o dia 13 de maio, ou seja: para os intelectuais negros do Grupo Palmares (1978), liderados por Oliveira Silveira (1941-2009), ter (re) significado a data alusiva à memória da luta negra para a morte de Zumbi dos Palmares (1655-1695), conforme pesquisou o historiador Deivison Campos, em contraponto à data do dia 13 de maio, identifica a importância simbólica dessa efeméride oficial, já que, sendo contra ou a favor, ela tornou-se o parâmetro do debate sobre qual data representava melhor o protagonismo negro na resistência à escravidão, e o reconhecimento político-social da liberdade, nos dias atuais, identificada no dia 20 de novembro (CAMPOS, 2006).

A democracia racial tinha como referência da liberdade o dia 13 de maio. Logicamente, jamais desconsideramos as ideias de negritude do TEN, que já em 1944, no Rio de Janeiro, remetia a uma cultura centrada nos valores culturais africanos. Contudo, o país e os meios de comunicação ainda eram restritos, naquela época, para fazerem com que esses valores se difundissem nas velocidades pensadas em nossos dias atuais por todo o Brasil. Portanto, concordamos com Emília Viotti da Costa que explica:

Em esboço, os fatos são suficientemente claros: um poderoso mito, a ideia da democracia racial - que regulou as percepções e até certo ponto as próprias vidas dos brasileiros da geração de Freyre - tornou-se para a nova geração de cientistas sociais um arruinado e desacreditado mito (COSTA, 1998:374).

A partir dos anos de 1950, com a denúncia das organizações negras e de seus líderes, passa-se a compreender as diferenças raciais e sociais em nosso país. Pois, anteriormente, como enfatiza Costa:

É óbvio que os brancos beneficiaram-se com o mito. Mas também é verdade que os negros beneficiaram-se igualmente, embora de uma maneira mais limitada e contraditória. A negação do preconceito, a crença no "processo de branqueamento", a identificação do mulato como uma categoria especial, a aceitação de indivíduos negros entre as camadas da elite branca, tornaram mais difícil para os negros desenvolver um senso de identidade como grupo. De outro modo, criaram oportunidades para alguns indivíduos negros ou mulatos ascenderem na escala social. Embora socialmente móveis, os negros tinham, entretanto, que pagar o preço por sua mobilidade: tinham que adotar a percepção que os brancos possuíam do problema racial e dos próprios negros. (Grifo Nosso)(COSTA, 1998:375). 
Certamente, essa tensão era sentida pelos líderes negros. Pois, como acreditar em uma democracia racial se, no cotidiano, o preconceito racial era e é sentido? A partir desse momento, a negociações políticas passam a ocorrer pela ação consciente da ideologia da negritude, formulada pelos líderes da comunidade negra que, para transformar os problemas materiais, necessariamente deveriam passar pela conquista do poder político, ao invés do reconhecimento, somente, da matriz africana na cultura negra brasileira.

Localizamos os anúncios das seguintes candidaturas de políticos negros, que participariam do pleito do dia 3 de outubro de 1950: José Bernardo da Silva, candidato a deputado pelo PTB, diretor da UHC, da cidade do Rio de Janeiro; Jael de Oliveira Lima, candidato a deputado pelo PSD e Isaltino Veiga dos Santos, candidato a vereador pelo PDC. Isaltino foi um dos presidentes da Frente Negra Brasileira (1931-1937). Abdias do Nascimento também saiu nas páginas de seu jornal como candidato. Ele iria disputar a vereança no Rio de Janeiro, pelo PSD; inclusive notamos que este partido foi o que mais saiu nas páginas do jornal, sinalizando para os interesses políticos eleitorais do intelectual negro e fundador do TEN. Abdias, não fora eleito (GOMES, 2008:308). Todavia, esses embates no centro do país são essenciais em nossa tese, visto que no Rio Grande do Sul, guardadas as devidas proporções, experimentou-se, por intermédio de seus protagonistas negros, experiências comparáveis a dos negros do eixo Rio-São Paulo, obviamente, que com as suas peculiaridades.

Os encontros realizados nesse contexto em que os aspectos sociais, culturais e políticos da identidade negra estiveram em pauta, possibilitou uma melhor interpretação das organizações negras e de suas lideranças sobre as situações vivenciadas pelas populações negras nas diversas regiões brasileiras, já que pesquisadores e militantes ou pesquisadores populares viajavam com suas representações por meio de navios para esses lugares sociais, que produziam documentos e trocavam experiências cotidianas, teóricas e práticas, de como compreender as situações envolventes à identidade negra nacional (GOMES, 2008:308).

Para Ivair Augusto Alves dos Santos, no período entre 1945 a 1964, viveu-se de modo singular, com a existência de um sistema multipartidário (SANTOS, 2002). A partir dessa fase democrática, passou também a existir, em alguns partidos políticos, a preocupação sobre a questão racial. Conforme Alves dos Santos:

Ao analisar os programas partidários, encontramos referências sobre a questão racial nos seguintes partidos políticos: Partido Trabalhista

\section{Em Tempo de Histórias}

Publicação do Programa de Pós-Graduação em História da Universidade de Brasília (PPGHIS/UnB) $\mathrm{N}^{\circ}$. 22, Brasília, Jan. - jul. 2013. ISSN 2316-1191 
Brasileiro (PTB), Partido Socialista Brasileiro (PSB) e Partido Democrata Cristão. Nos maiores partidos deste período, o Partido Social Democrático $(P S D)$ e a União Democrática Nacional (UDN), partidos conservadores, não constava nenhuma menção ou citação em seus programas sobre a questão racial. Entretanto, foram os parlamentares da UDN os autores da lei que dispunha sobre os atos de discriminação e preconceito racial e de cor que, durante décadas, permaneceu como o único recurso legal, a Lei Afonso Arinos. (Grifo Nosso) (SANTOS, 2002:59).

Portanto, o PTB contemplava as questões raciais em suas diretrizes, enquanto o PSD, mais conservador, mantinha-se neutro quanto a esse assunto. Abdias do Nascimento, importante militante do movimento negro brasileiro, concorreu nas eleições da cidade do Rio de Janeiro em 1950, ligado ao PSD, conforme informou L.C. Pinto (1953:284).

Salientamos que o político Carlos Santos (1904-1989), líder negro e operário, chegou ao legislativo gaúcho no ano de 1951 para assumir, após suplência, a vaga de Tarso de Moraes Dutra (1914-1983), pois Dutra assumiu a vaga na Câmara Federal, abrindo seu posto a sua nomeação. Na ocasião, Santos era político vinculado ao PSD, mesma situação vivenciada pelo intelectual negro Abdias do Nascimento. Porém, mais adiante, iria filiar-se à dominante agremiação de ideologia trabalhista, o PTB. Tal situação, provavelmente era influenciada pela necessidade própria de sua articulação política ser mais próxima das massas populares e das questões nacionais, identificadas na plataforma petebista ${ }^{14}$.

O PTB, partido com forte marca getulista desde a sua concepção e fundação, apresentou um programa que traduz, quase na integridade, o projeto de Getúlio Vargas para o Brasil. O programa propunha entre outras ações a defesa dos direitos trabalhistas; políticas sociais, voltadas para a garantia de emprego e à qualificação do trabalhador. ${ }^{15}$

Politicamente e socialmente, é importante salientar que o PTB era um partido que representava o trabalhismo, independente da origem étnica desse trabalhador, sendo localizadas suas influências em sociedades polonesas, ucranianas, alemãs e russas de Porto Alegre (FORTES, 2004:117-177). Essa relação era limitada quanto à influência dessas sociedades no seio do partido trabalhista, fossem elas sociedades étnicas, beneficentes ou até

\footnotetext{
${ }^{14}$ O político Carlos Santos, nascido em Rio Grande, interior do RS, durante sua vida pública de cinquenta anos (1932-1982), exerceu os cargos de deputado e governador do Rio Grande do Sul, em 1967 pelo MDB. Foi líder sindical e fundador de associações negras (GOMES, 2012).

${ }^{15}$ Programa do PTB - Arquivo Getúlio Vargas - GV45000/1 - FGV - CPDOC -Rio de Janeiro. Ver DELGADO, Luciana de Almeida Neves. Brasil: 1954 - prenúncios de 1964. Varia História, Belo Horizonte, vol. 21, n 34: p.484-503, Julho 2005. Disponível em: < http://www.scielo.br/scielo.php?pid=S010487752005000200013\&script=sci_arttext>. Acesso em: 01 out.2012. 
sindicatos de classe, pois suas participações eram tuteladas e controladas e, conforme Ângela de Castro Gomes existiu um "pluralismo limitado":

O PTB, assim como os sindicatos no Brasil, nasceu sob a chancela de um estado autoritário, para atuar em um regime não mais autoritário, mas certamente ainda conservador. Projetos de participação política mais mobilizadores e instrumentos de representação mais autônomos não tinham espaço nesta espécie de "pluralismo limitado" do pós-45. (Grifo Nosso) (FORTES, 2004:437).

Destaca-se que o PTB, a partir da ideologia do trabalhismo e de um consenso com outros grupos subordinados, buscou difundir o seu projeto político, mantendo sua hegemonia por meio de uma liderança perante esses grupos. Eis que surge uma questão relacional, em nossa opinião, entre esse partido e as sociedades étnicas porto-alegrenses e gaúchas, com isso, mantendo um "equilíbrio instável" e tendo que ceder, em determinados momentos, em algumas condições para exigir outras; com isso, elaborando estratégias para concretizar o seu interesse e objetivo imediato, que era ter sucesso no pleito do Estado do Rio Grande do Sul (Gramsci apud HALL, 2003:295-334). Essa situação também foi analisada por nós para que entendêssemos e identificássemos os interesses do grupo negro, na ocasião representado pela Sociedade Floresta Aurora, com a realização do Primeiro Congresso Nacional do Negro, realizado em Porto Alegre, no ano de 1958, como veremos mais adiante. Em nossas pesquisas de mestrado identificamos, por meio de entrevistas orais com pessoas frequentadoras de associações negras porto-alegrenses, a forte influência exercida pelo PTB na comunidade negra. A maioria citava essa ligação pela identificação do discurso vinculado ao trabalho (GOMES, 2008).

Entretanto, o PTB mantinha o controle dessas relações, exercendo a hegemonia, pois, de um lado, passou a representar, como liderança política, a vontade coletiva deste e dos outros grupos que passara a tutelar, e de outro, a própria ideologia nacionalista serviu como um ingrediente aglutinador entre o Partido e os grupos étnicos que vieram para o Brasil entre os anos 1930, 1940 e 1950, tais como polacos, russos, alemães e ucranianos, além dos próprios negros que, a partir da Frente Negra Brasileira, exigiam o reconhecimento de suas raízes como formadora do Brasil, na década de 1930. O que o PTB porto-alegrense utilizou, em última análise, foi a estratégia iniciada por Getúlio, em 1933, ao receber os líderes da Frente Negra no Palácio do Governo, com intuito de formar uma aliança em torno de um projeto nacional, que culminou com o decreto do Estado Novo. O que precisamos entender é 
se esta estratégia foi utilizada por Getúlio e pelo próprio PTB, partido criado por ele também a partir da relação com outras etnias e classes que viviam em nosso país. O partido passa e exercer a vontade coletiva das massas trabalhadoras. A hegemonia pode ser pensada a partir do Bloco Histórico que abrange a estrutura - o campo econômico - e a superestrutura - o campo da ideologia. A partir desses dois domínios, temos caracterizada a hegemonia, localizada no PTB por meio do nacionalismo econômico; visando às estatizações e à produção e sendo controlada pelo intervencionismo direto do estado, seja na difusão da ideologia nacionalista, a partir dos órgãos culturais, políticos e educativos, ou como a bandeira da nacionalização do ensino, em que a língua nas escolas deveria ser a portuguesa.

Conforme Gramsci:

Embora cada partido seja a expressão de um grupo social e de um só grupo social, ocorre que, em determinadas condições, determinados partidos representam um grupo social na medida em que exercem uma função de equilíbrio e de arbitragem entre os interesses do seu grupo e os outros grupos, e na medida em que buscam fazer com que o desenvolvimento do grupo representado se processe com o consentimento e com a ajuda dos grupos aliados (...) (GRAMSCI, 1995:22).

O PTB, na década de 1950, manteve a sua hegemonia até o final da experiência democrática, mantendo representante no poder executivo e, constantemente, nos parlamentos municipais - a exemplo de Porto Alegre e da assembleia legislativa do Estado. Os setores populares, também passaram a ganhar espaço, no período com o aumento da participação de agremiações que mantinham em seus projetos preocupações sociais e trabalhistas.

Nessa década as organizações negras gaúchas Marcílio Dias, Prontidão, Treze de Maio de Santa Maria, Sociedade Flor do Sul, de Taquara, Estrela do Oriente, de Rio Grande, associações negras de Pelotas etc. seguiam as suas atividades esportivas, festivas, culturais, educativas e reivindicativas (PEREIRA, 2008).

Em 1958, ocorreu o Primeiro Congresso Nacional do Negro, organizado pela Sociedade Beneficente Floresta Aurora. Este encontro tem como diferencial dos demais o termo "nacional" em sua nomenclatura. A atividade foi realizada no estado do Rio Grande do Sul, na cidade de Porto Alegre. Notaremos que o termo "nacional", além de ser o diferenciador da terminologia entre as duas atividades, denota, ainda, uma transformação importante nos interesses de seus organizadores, já que existiu uma forte influência do PTB em sua composição. 
Esse importante acontecimento, no capital gaúcha recebeu delegações dos estados do Paraná, Minas Gerais, Rio de Janeiro, Santa Catarina, São Paulo, Distrito Federal e interior, contou, também, com a presença de estudiosos, pesquisadores, intelectuais brancos e negros e a comunidade. Durante o encontro, foram debatidos três temas centrais: a necessidade de alfabetização frente à situação atual do Brasil, a situação do homem de cor na sociedade e o papel histórico do negro no Brasil e em outros países. Esses temas foram distribuídos em seis dias, do dia 14 ao dia 19 de setembro. Os deputados petebistas Armando Temperani Pereira e Coelho de Souza, os professores da Escola de Engenharia da UFRGS (instituição em que se formou Leonel Brizola que, na época, estava concorrendo ao governo do Rio Grande do Sul contra Walter Peracchi Barcelos), Dr. Luiz Lesseigner de Faria, Dr. Darci Conde Salgado e Dr. Manoel Luiz Leão, o presidente da Floresta Aurora, Walter Santos e representantes do Jornal Correio do Povo de Porto Alegre, além de estudiosos da temática como Dante Laytano etc., discutiram, com a presença de grande público nos locais do congresso, sobre a realidade do negro e do africano no estado, no Brasil e no mundo. Nesse período ocorria, a nível internacional, a independência de muitos países africanos. ${ }^{16} \mathrm{O}$ Primeiro Congresso Nacional do Negro foi realizado na Câmara de Vereadores de Porto Alegre e nos salões de festas da organização negra.

Defende-se que esse encontro foi importante para os interesses do PTB de Brizola, que veio a se eleger governador uma semana depois dessa atividade, contando com apoio das entidades classistas e étnicas. O congresso também foi relevante para a comunidade negra regional e nacional que, após o encontro, foi contemplada pela "Campanha Nacional de Alfabetização", já que, na época, 70\% dos negros brasileiros eram analfabetos. Para a Sociedade Floresta Aurora, o encontro foi materialmente importante, pois dias após o conclave a entidade alterou de sede social, localizada na rua Gen. Lima e Silva, transferindose com o auxílio de incentivos do estado e de políticos petebistas para o bairro Cristal de Porto Alegre (GOMES, 2008).

\section{Das demandas educativas às Ações Afirmativas}

\footnotetext{
${ }^{16}$ No plano internacional, a década de 1950 é marcada pelos movimentos iniciais de descolonização de territórios africanos sob jugo europeu e em torno dos debates de integração racial. Guiné tornou-se independente em 1958; em 1959 os países africanos movimentavam-se em seus processos de autonomia. Na Conferência de Bamako, o Senegal e o Sudão Francês formavam a Federação do Mali, independentes. Daomé, Niger, Alto da Volta, Costa do Marfim e Togo tornam-se independentes em 1960. "Os novos países surgidos da divisão administrativa colonial do pós-guerra eram uma realidade” (RIBEIRO, 1998:51-72).
} 
No Brasil, desde a abolição, as demandas referentes às melhorias sociais no que tange as condições das populações negras, quando ocorreram, transitaram lentamente. "O espirito revolucionário teve que executar em poucos anos uma tarefa que havia sido desprezada durante um século, uma grande reforma social...a verdade, porém, é que a corrente abolicionista parou no mesmo dia da abolição e no dia seguinte refluía" (NABUCO, 1966:144-145).

Portanto, a comunidade negra livre reivindicou suas necessidades, visando à sua inserção social desde a abolição perpassando pelas décadas demonstradas. Pois não foi mera coincidência a aproximação dos líderes negros com o trabalhismo, nacionalismo e a democracia racial como demonstramos por meio de Abdias do Nascimento (1914-2011) e Carlos Santos (1904-1989).

Quanto ás organizações negras, as mesmas serviram de locais de encontros de representantes desta identidade, que iniciaram aulas de alfabetização apontando estrategicamente a integração das comunidades negras na sociedade abrangente por intermédio da educação Desde as aulas de alfabetização do Teatro Experimental do Negro até a Campanha Nacional de Alfabetização iniciada no Congresso do Negro de Porto Alegre, tem-se a educação como objetivo material das demandas inclusivas pensadas pelos intelectuais negros. Ressalta-se que essas ações demandas constituíram a base das lutas negras por acesso a educação.

A educação de seus pares foi uma prática constante nas organizações negras de Porto Alegre e do país. Na capital dos gaúchos as sociedades Floresta Aurora, Marcilio Dias e Satélite Prontidão, desde o final do século XIX mantinham em suas sedes cursos de alfabetização (PEREIRA, 2008). A instrução e a educação eram atividades frequentes também nas Frentes Negras, independentemente da cidade em que ela existiu a mesma oferecia cursos e seminários para os seus associados.

Carlos da Silva Santos (1904-1989), primeiro governador negro em exercício do Rio Grande do Sul e deputado por diversas legislaturas, também foi integrante da Sociedade Floresta Aurora e respeitava muito enquanto negro e político a educação. Por ocasião da fundação do Centro Cultural Marcílio Dias, notamos esta situação.

Na fundação da organização negra, datada do dia 11 de junho de 1936, ele, através de um pronunciamento, dignificou a educação. A instalação oficial do Centro ocorreu no Teatro 
7 de setembro, na cidade de Rio Grande. Naquela noite, o então deputado classista, encerrou o seu discurso da seguinte maneira:

Salve, instrução, deusa da felicidade, vida, doçura e esperança nossa, salve. Bradam por ti os filhos das trevas. Por ti suspiram e gemem milhões de criaturas que se enlodaram nos paués do analfabetismo. Eia, pois, advogada dos fortes e dos valorosos, estes olhos luminosos a nós volvei e depois deste desterro de ignorância e de todo maligno cortejo de que se acerca o analfabetismo, mostrai-nos o livro, o saber, a educação, a felicidade, o patriotismo e a liberdade, frutos benditos do teu ventre. Para a glória do Brasil, deusa da instrução. Assim seja. (SANTOS, 1937:99).

A organização UHC, conforme pesquisas de Joselina Silva (2003), tinha como um dos seus objetivos, expressos no artigo $1^{\circ}$ do estatuto, no capítulo das finalidades, conforme citado anteriormente: "elevar o nível intelectual das pessoas de cor em todo o território nacional". O TEN, também teve as suas ações encerradas no período de exceção. Tinha como objetivos: contestar a discriminação, formar atores afro-brasileiros, reivindicava a diferença e não apenas integrar-se a sociedade, reconhecimento do valor civilizatório da herança africana, além de realizar cursos de alfabetização nos morros cariocas (NASCIMENTO, 2004: 210). Conforme Ironides Rodrigues, integrante do TEN: o grupo tinha por base o teatro como um veículo poderoso de educação popular. Tinha sua sede num dos salões da União Nacional dos Estudantes, onde aportavam, dos subúrbios e dos vários pontos da cidade, operários, domésticas, negros e brancos de várias procedências humildes (Ceva apud RODRIGUES, 2006:58). Ou seja, tanto a UHC quanto o TEN nos anos 40, 50 e inicio dos 60 mantinha em suas linhas de atuação a alfabetização como estratégia de inserção social das populações negras atendidas.

Por meio desse breve histórico, elucidou-se a luta da população negra e de seus líderes pela educação. Situação que, guardadas proporções, na contemporaneidade remete-nos, ao tema das ações afirmativas. Mesmo que no passado este termo jurídico jamais tenha sido utilizado pelas organizações negras. Uma ação afirmativa visa reparar necessidades de grupos que por algum motivo tiveram suas condições materiais historicamente prejudicadas. Nos países onde já foram implementadas Inglaterra, Canadá, Índia, Alemanha, Austrália, Nova Zelândia, Malásia, entre outros, elas visam oferecer aos grupos discriminados e excluídos um tratamento diferenciado devido à sua situação de vítimas do racismo (MUNANGA, 2003:117). Nos Estados Unidos ações deste tipo tiveram origem nos anos de 1960, já que os negros norte-americanos eram proibidos de andar livremente nas ruas, ônibus e frequentar 
escolas, em fim de viverem dignamente. Naquele contexto surgiram as lutas pelos direitos civis lideradas por Martim Luther King (1929-1968), Rosa Park (1913-2005), entre outros, resultando na política de cotas, decretadas pelo presidente estadunidense John F. Kenndy (1917-1963) (NILMA GOMES, 2005; PETRONILHA, 2003; SILVA, 2003).

O Presidente John Kennedy foi o primeiro governo americano que se empenhou em articular as ações afirmativas. Na Ordem Executiva (EO) 10 925, que dirigiu Kennedy aos contratados federais afirma que deve "existir a ação afirmativa para garantir os empregados e empregadores que sejam tratados durante o seu emprego, sem ter em conta a sua raça, cor, credo ou origem nacional” (SOMERS; JONES, 2009:246).

Essa lei era "uma preocupação para se evitar as discriminações daqueles que foram historicamente discriminados, antes de uma definição especifica de cotas ou preferências" (SILVA, 2008:28). Desde o início de sua implantação nos anos 60, logo após a assinatura de um decreto executivo pelo presidente John Kennedy, que determinava a inserção dos negros eles lutaram pelo sistema educacional de qualidade (SILVÉRIO, 2002:238). Todavia, essas ações somente iriam ser planejadas e executadas com prazos, objetivos e metas, em 1968, com Lyndon Johnson (1908-1973) e, em 1971, com Robert Nixon (1939-2002).

Concorda-se com Munanga quando diz:

as experiências feitas pelos países que convivem com o racismo poderia servir de inspiração ao Brasil, respeitando as peculiaridades culturais $e$ históricas do racismo à moda nacional. Podemos, sem copiar, aproveitar das experiências positivas e negativas vivenciadas por outros para inventar nossas próprias soluções, já que estamos sem receitas prontas para enfrentar nossas realidades raciais (MUNANGA, 2003:118).

A lei 10.639 promulgada em 2003, em seu texto completo tornou obrigatório nos estabelecimentos de ensino fundamental e médio, oficiais e particulares o ensino sobre História e Cultura Afro-Brasileira. O conteúdo programático a que se refere o decreto deverá ser ministrado no âmbito de todo o currículo escolar, em especial nas áreas de Educação Artística e de Literatura e Histórias Brasileiras. Os programas devem contemplar o estudo da História da África e dos Africanos, a luta dos negros no Brasil, a cultura negra brasileira e o negro na formação da sociedade nacional, a contribuição do povo negro nas áreas social, econômica e políticas pertinentes à História do Brasil. A Lei também instituiu o dia 20 de novembro como "Dia Nacional da Consciência Negra". Todas essas assertivas são fatores 
incidentes das demandas negras bem como da promulgação das ações afirmativas (AA). Uma das mais polêmicas leis vinculadas às essas ações foi a criação dos sistemas de políticas de cotas no Ensino Superior. Desde o início de suas existências as lideranças negras preocuparam-se com educação e alfabetização como se fosse uma marca estrutural de suas reivindicações. Torna-se pertinente identificar na transposição dessas demandas, relacionadas ás sociedades civis negras por meio de suas lideranças, para as políticas afirmativas de Estado. Porém, assim como as negociações se deram nas fissuras e nas tensões sociais, as suas aplicações jamais seriam diferentes.

\section{Considerações Finais}

A lei 10.639/03, desde 2008, acrescida das temáticas indígenas, resultou na Lei 11.645/08, é considerada por lideranças negras atuais como uma das principais políticas conquistadas. Entretanto, esses mesmos representantes constantemente reclamam que desde a sua publicação, a Lei 10.639, datada do ano de 2003, não vem sendo aplicada. Situação que vem se repetindo em várias regiões do Brasil, justificada entre outras situações, em nosso entendimento, pela falta de institucionalização da referida lei. ${ }^{17}$ A institucionalização é um resultado capaz de sobreviver aos seus atores e ser renovado por outras gerações (Arendt apud AVRITZER, 2008). Ou seja, mesmo ela sendo fruto das negociações políticas advindas das ideologias citadas, quanto aos mecanismos indispensáveis à sua institucionalização ela vem encontrando limites.

Reconhecemos que muito deve ser realizado quanto a isto. Entende-se que as reivindicações dos movimentos negros estão contribuindo para a ampliação qualificada do debate das desigualdades sociais em nosso país. Historicamente, devemos considerar as contribuições de intelectuais brancos e negros, acadêmicos, militantes e formadores de opinião que no passado negociaram e fizeram na fissura das relações sociais - embora muitas vezes tuteladas - inovações em suas formas reivindicativas. Os congressos e as solicitações de apoio a políticos, realizadas desde a época do trabalhismo, comprovam essa condição, já que, na dificuldade de adentrar nas estruturas do poder de Estado, os grupos negros organizaram

\footnotetext{
${ }^{17}$ O COPENE - Congresso dos Pesquisadores e Pesquisadoras Negros e Negras do Brasil, reuni pesquisadores de todo o Brasil no intuito de promover debates acadêmicos sobre os problemas cotidianos da população negra. $\mathrm{O}$ encontro se caracteriza pela qualidade e quantidade das comunicações e conferências. Uma das reclamações mais constantes dos participantes de todas as regiões do Brasil é para a falta de institucionalização da Lei 10.639/03 nos sistemas regionais de educação. Para saber mais sobre o COPENE consulte: http://www.abpn.org.br/. Acesso em 10 de out. 2012.
} 
convenções e reuniões em que se propunham alternativas viáveis para combater os problemas enfrentados pelas populações negras na luta por prestígio, reconhecimento e melhorias sociais.

Se em nosso país não existissem problemas desta ordem, desde o período analisado, o que explicaria a lei 1.390, de 3 de julho de 1951, chamada Afonso Arinos, que incluiu como contravenção penal o preconceito de raça ou cor? Ou a lei 7.716, de 5 de janeiro de 1989, conhecida como Lei Caó, que definiu como crime práticas resultantes de preconceito de raça ou cor?

A Lei 10.639/03, o Estatuto da Igualdade Racial, as próprias politicas de cotas nas universidades públicas e no serviço publico são considerados resultados das reivindicações, das tensões e negociações políticas da comunidade negra e de seus representantes com outros atores políticos, explicadas por fatores culturais e sociais diversos como abertura política pósEstado Novo, pressões de grupos organizados, luta pelos direitos civis e humanos e a afirmação política negra nos finais dos anos de 1970.

No Brasil, a SEPPIR - Secretaria de Promoção da Igualdade Racial também no ano de 2003, contou no ato de sua fundação com a presença de Abdias do Nascimento, intelectual simbólico das demandas negras, trabalhista histórico do PTB e do PDT, em seu pronunciamento invocou que a criação da SEPPIR: "devia-se a luta dos ancestrais negros rebeldes e dos orixás africanos", identificando-se nesse discurso os valores ideológicos da negritude, ideais da negritude presente na concepção desta instituição de Estado, com status de Ministério. O fato desta Secretaria bem como das promulgações das Ações Afirmativas terem se dado no mesmo ano da assunção do Partido dos Trabalhadores ao poder do Estado brasileiro, identifica novamente a relação ideológica do trabalho com a negritude. Situações que remontam à realidade, em que surgiu-nos a seguinte reflexão: qual foi o grupo que trabalhou arduamente nesse país, sem desmerecer aos demais, desde os séculos XVI?

\section{Referências Bibliográficas}

Fontes Transcritas

Jornal A Alvorada, Pelotas, ano 53, n.22, 1951, p.01.

\section{Bibliográficas}

ALTHUSSER, Louis. Aparelhos ideológicos de Estado. Rio de Janeiro: Gral, 1992. 
AVRITZER, Leonardo. Ação, fundação e autoridade em Hannah Arendt. Revista Lua Nova, São Paulo, 68, 2006, p. 147-167.< http://www.scielo.br/pdf/ln/n68/a06n68.pdf >. Acesso em jul.2012

BENTO, Maria Aparecida. Branqueamento e Branquitude no Brasil. Psicologia Social do Racismo. Estudos sobre branquitude e branqueamento no Brasil. 1.ed. Petrópolis RJ: Vozes, 2002, p. 189.

BERND, Zilá. A questão da negritude. São Paulo: Brasiliense, 1984.

CAMPOS, Deivison Moacir Cezar. O Grupo Palmares (1971-1978): Um movimento negro de subversão e resistência pela construção de um novo espaço social e simbólico. 195 f, Porto Alegre, 2006. (Mestrado em História) - Programa de Pós-Graduação em História - PUCRS

CARNEIRO, Edison. Ladinos e Crioulos. S ed. Rio de Janeiro: Ed. Civilização Brasileira, 1964, p.115-116.

CEVA, Antonia Lana de Alencastre. O negro em cena: a proposta pedagógica do Teatro Experimental do Negro. 124 f., Rio de Janeiro, 2006. (Mestrado em Educação) PUC-RJ.

CHAUÍ, Marilena. O que é ideologia. Ed. Brasiliense, 30 edição. São Paulo, 1989, p.21-25.

CLAY, Vinícius. O Negro em O Estado da Bahia: De 09 de maio de 1936 a 25 de janeiro de 1937. 2006. Disponível em: http://www.facom.ufba.br/pex/viniciusclay.doc/ Acesso em: 10 de fev. 2008

COSTA, Emilia Viotti. Da Monarquia à República - Momentos decisivos. 7 ed. São Paulo: Editora UNESP, 1998, p.490.

DOMINGUES, Petrônio. Movimento da negritude: uma breve reconstrução histórica. Mediações - Revista de Ciências Sociais, Londrina, v. 10, n.1, p. 25-40, jan.-jun. 2005.

DOMINGUES, Petrônio. Movimento Negro Brasileiro: alguns apontamentos históricos. Revista Tempo, n 23,

Rio de Janeiro, UFF, 2007, p. 108.

FANON, Frantz. Pele negra, máscaras brancas. Trad. Renato Silveira. Salvador: UDUFBA, 2008.

FERREIRA. Jorge. Ao mestre com carinho, ao discípulo com carisma: as cartas de Jango a Getúlio. In GOMES, Ângela de Castro. Escritas de si, escritas da História. 1 ed. Rio de Janeiro: FGV, 2004, p.279-294.

FORTES, Alexandre. Nós do Quarto Distrito. A Classe trabalhadora Porto-Alegrense, e a Era Vargas. 1 ed. Caxias do Sul: EDUCS-Garamond, ANPUH-RS, 2004, p.20-28.

GOMES, Ângela de Castro. A invenção do trabalhismo. 1 ed. Rio de Janeiro: Vértice, 1988, p.343.; FAUSTO, Boris. História concisa do Brasil. 3 ed. São Paulo: EDUSP/Imprensa Oficial, 2002, p.328.

GOMES, Arilson dos Santos Gomes. O Primeiro Congresso Nacional do Negro e a sua importância para a integração social dos negros brasileiros e a ascensão material da Sociedade FlorestaAurora.pdf. RBHCS - Revista Brasileira de História e Ciências Sociais, v. 01, p. 01-18, 2009.

GOMES, A.. A formação de oásis: dos movimentos frentenegrinos ao Primeiro Congresso Nacional do Negro em Porto Alegre - RS (1931-1958). Em tempo de histórias, Brasília, Vol. 0, N. 14, fev. 2011. Disponível em: <http://seer.bce.unb.br/index.php/emtempos/article/view/2729/2285>. Acesso em: 02 Abr. 2013.

GOMES, Arilson dos Santos. A formação de oásis: dos movimentos frentenegrinos ao Primeiro Congresso Nacional do Negro em Porto Alegre - RS (1931-1958). 310f. Porto Alegre, 2008. (Dissertação de Mestrado em História) - Programa de Pós-Graduação em História - PUCRS.

GOMES, Arilson dos Santos. A identidade cultural afro-brasileira como meio de negociação entre os grupos sociais: análises em torno da publicação do livro Cartas de Edison Carneiro a Artur Ramos (1936-1938). 2011, p.5-22 (Prelo).

GOMES, Arilson dos Santos. Os Akins do Sul: da participação dos negros na política do Rio Grande do Sul à homenagem ao mestre salas dos mares. Revista OPSIS - UFG, Goiás, Catalão, Vol. 12 nº1: p.129-145, novembro 2012. <http://www.revistas.ufg.br/index.php/Opsis/article/view/17396>. Acesso em: 01 dez.2012.

GOMES, Nilma Nilo. Alguns termos e conceitos presentes no debate das relações raciais no Brasil: uma breve discussão. Educação Antirracista - Caminhos abertos pela Lei Federal 10.639/03. Brasília: Coleção Educação para Todos. SECAD/MEC, 2005.

GRAMSCI, Antônio. Os intelectuais e a organização da cultura. 2 ed. Rio de Janeiro: Ed. Civilização Brasileira, 1995, p.22.

GRAMSCI. Maquiavel, a política e o Estado Moderno, 1980, p.09-25, e de HALL, Stuart. A relevância da Gramsci para o estado de raça e etnicidade, 2003, p.295-334.

HALL, Stuart. Da Diáspora: identidades e mediações culturais. Belo Horizonte: UFMG, 2003.

MEMMI, Albert. Retrato do colonizado precedido pelo retrato do colonizador. Trad. Roland Corbisier e Mariza Pinto Coelho. $3^{\text {a }}$ ed. Rio de Janeiro: Paz e Terra, 1989.

MOTA, Carlos Guilherme. Ideologia da Cultura Brasileira (1933-1974). 4 ed. São Paulo: Editora Ática, 1980, p.156-160. 
MÜLLER, Liane Suzan. “As contas do meu rosário são balas de artilharia” - Irmandade, jornal e sociedades negras em Porto Alegre 1889-1920. 253 f. Porto Alegre, 1999.(Dissertação de Mestrado em História), PPGH/PUCRS.

MUNANGA, Kabengele. Negritude; usos e sentidos. $2^{\text {a }}$ ed. São Paulo: Ática, 1988.

MUNANGA, Kabengele. Políticas de ação afirmativa em benefício da população negra no Brasil: um ponto de vista em defesa das cotas in SILVA, Petronilha Beatriz Gonçalves; SILVEIRO, Valter Roberto. Ações Afirmativas - entre a injustiça simbólica e a injustiça econômica. Brasília, INEP, 2003, p.117-128.

NABUCO, Joaquim. Minha Formação. Rio de Janeiro: Ediouro, 1966, p.144-145.

NASCIMENTO, Abdias do. Minha candidatura. Fac-Símile Jornal Quilombo. Jul.1950, p.83.

NASCIMENTO, Abdias. O negro revoltado. 1 ed. Rio de Janeiro: Editora Nova Fronteira, 1982.

NASCIMENTO, Abdias. Reflexões sobre o Movimento Negro no Brasil, 1938-1997. In: GUIMARÃES, Antônio Sérgio Alfredo, HUNTLEY, Lynn. Tirando a máscara: ensaios sobre o racismo no Brasil. 1 ed. São Paulo, Paz e Terra, 2000, p.210.

NASCIMENTO, Abdias; NASCIMENTO, Elisa Larkin. O negro e o Congresso Brasileiro. In MUNANGA, Kabenguele (Org.). O negro na sociedade brasileira: resistência, participação, contribuição. 1 ed. Brasília: Fundação Cultural Palmares - MINC, V.1, 2004, p.223.

PEREIRA, Eliane. Floresta Aurora: fundação e função até 1988. Porto Alegre, 1986. (Monografia). PUCRS p.6.

PEREIRA, Lúcia Regina Brito Pereira. Cultura e Afro-descendência: Organizações Negras e suas estratégias educacionais em Porto Alegre (1872-2002). 309f. Porto Alegre, 2008. (Tese de Doutorado em História) Programa de Pós-Graduação em História - PUCRS.

PINTO. Luiz Antonio Costa. O Negro no Rio de Janeiro. São Paulo: Companhia Editora Nacional, 1953, p.284. PORTELLI, Hugues. Gramsci e o Bloco Histórico. Paz e Terra: Rio de Janeiro, 1983.

RÉMOND, René. Por uma história política. Editora FGV: Rio de Janeiro, 2003.

RIBEIRO, Luiz Dario. Descolonização africana. Revista Ciências e Letras FAPA 21/22, África Contemporânea. Porto Alegre: Ed. Ponto e Vírgula. Novembro de 1998, p.51-72.

SADER, Éder. Um rumor de botas - Ensaios sobre a militarização do Estado na América Latina. Coleção Teoria e História 11. São Paulo: Editora Pólis, 1982, p.138.

SANTOS, Carlos. Sucata. Porto Alegre: GLOBO, 1937.

SANTOS, Ivair Augusto Alves dos. O movimento negro e o Estado: $O$ caso do Conselho de Participação e Desenvolvimento da Comunidade Negra no Governo de São Paulo. 1 ed. São Paulo: imprensa oficial, 2002.

SANTOS, Sales Augusto dos. "O negro no Poder" no Legislativo: Abdias do Nascimento e a discussão racial no Parlamento brasileiro. MENDES, Amauri; SILVA, Joselina (Orgs.) O Movimento Negro Brasileiro - escritos e sentidos de democracia e justiça social no Brasil. Belo Horizonte: Nandyala, 2009. p.127-163.

SCHILLING, Voltaire. A Luta pelos direitos civis: de Abraham Lincoln a Martin Luther King - América: $1863-$ 1963. Porto Alegre: $s d, 2003$.

SILVA, Cidinha. Ações Afirmativas em educação. Experiências brasileiras. São Paulo: Selo Negro, 2003.

SILVA, Fernanda Oliveira. Os negros, a constituição de espaços para os seus e o entrelaçamento desses espaços: associações e identidades negras em Pelotas (1820-1943). (Mestrado em História) - Programa de PósGraduação em História - PUCRS, Porto Alegre, 2011.228 p.

SILVA, Joselina da. A União dos Homens de Cor: aspectos do movimento negro dos anos 40 e 50 . Rio de Janeiro, 2003. Estudos Afro-Asiáticos. Vol.25. $\mathrm{n}^{\circ} 2$ p.215-235. Disponível em: <http://www.scielo.br/pdf/eaa/v25n2/a02v25n2.pdf>. Acesso em: mai. 2006.

SILVA, Petronilha Beatriz Gonçalves; SILVEIRO, Valter Roberto. Ações Afirmativas - entre a injustiça simbólica e a injustiça econômica. Brasília, INEP, 2003.

SOMERS, Patrícia; JONES, Catherine. Ações afirmativas na Educação Superior: o que acadêmicos brasileiros podem aprender da experiência americana. Educação, Porto Alegre, v. 32, n. 3, p. 246-251, set./dez. 2009. < http://revistaseletronicas.pucrs.br/ojs/index.php/faced/article/view/5770/4207>. Acesso out.2012.

WEFFORT, Francisco. Origens do sindicalismo Populista. Estudos Cebrap, nº, 1973.

WINOCK, Michel. As ideias políticas. RÉMOND, René. Por uma história política. Editora FGV: Rio de Janeiro, 2003, p271-290.

ZUBARAN, Maria Angélica. Comemorações da liberdade: lugares de memórias negras diaspóricas. Anos 90 Revista do PPG em História da UFRGS. V. 15, n27, 2008. p.161-187. Disponível em: <http://seer.ufrgs.br/anos90/article/view/6743/4045>. Acesso em: 11 mai. 2011. 